\title{
Development of a Multimedia Toolkit for Engineering Graphics Education
}

\author{
doi:10.3991/ijet.v4i3.639 \\ M. H. Zgoul and M.I. Kilani \\ University of Jordan, Amman, Jordan
}

\begin{abstract}
This paper focuses upon the development of a multimedia toolkit to support the teaching of Engineering Graphics Course. The project used different elements for the toolkit; animations, videos and presentations which were then integrated in a dedicated internet website. The purpose of using these elements is to assist the students building and practicing the needed engineering skills at their own pace as a part of an e-Learning solution. Furthermore, this kit allows students to repeat and view the processes and techniques of graphical construction, and visualization as much as needed, allowing them to follow and practice on their own.
\end{abstract}

Index Terms—engineering graphics, multimedia, e-Learning

\section{INTRODUCTION}

Recent technological innovations and the ever growing popularity and availability of the Internet, are the driving forces behind the development of numerous applications and projects in the field of technology-mediated education [1]. Furthermore, the massive growth of knowledge and the increasing number of knowledge seekers and scholars call for innovative solutions for the successful dissemination of information.

In a traditional approach for teaching, an instructor gives his students the knowledge they will need towards becoming Engineers. However, students can substantially improve their ability to gain more information when using non-traditional approaches. It is particularly essential to use such non-traditional approaches when teaching courses that require building skills; basic and advanced [2].

Interactivity, visualizations and animations are essential in engineering education. These with the power of the internet can be published and made available to knowledge seekers all over the globe. Animations are evidently more effective and have a positive impact on students when compared to traditional illustrations and graphics, particularly when handling complex systems [3, 4].

An actual case study is presented in this work; the engineering graphics course at the University of Jordan which is offered to all engineering specialties. This skills building course is offered to all first year students as a 3credit hour course. As a result of the large growth in engineering students' number at the university, this skills building course became a burden and started to cost a lot more than it was originally intended. Other issues associated with large numbers of students and hence large number of different tutorial sessions included the lack of consistency in material delivery and to the difficulty to supervise students and to respond to their individual needs

This motivated the search for an effective method to streamline the material delivery and provide a supplementary self-learning toolkit for students in the Engineering Graphics Course. A multi-media toolkit represents an advanced and effective method that encompasses the ease in presentation and the adaptive self-learning capability. It assists the students in comprehending the basic concepts and serves as a reference for proper dissemination of the material taught in class. It is anticipated that this project will open the way to establish a solid base for enhancing our instruction methods as well as our capability as a provider of education not only for our students but for students all over the world.

\section{OBJECTIVE}

The purpose of this project is to develop a multimedia toolkit including animations, videos, presentations and an internet website that will be made available to students enrolled in the engineering graphics course at the University of Jordan. These tools will assist students to practice and build the required skills at their own pace. Moreover, these tools, when developed will be of help to all engineering students not only in Jordan but also to all engineering students worldwide. Furthermore, this webbased course will cut down the time required to cover the theoretical content which allows extra time to do a larger number of tutorials. It also enhances the learning experience and brings the student much closer to a better understanding of the content by making this content available in an electronic self-explanatory form that could be accessed anywhere and at anytime. The extensive use of ready-made graphics helps to visualise the concept and thus brings it closer to the student.

\section{FRAMEWORK FOR MULTIMEDIA DEVELOPMENT}

Multimedia is any communication tool that conveys information, or that allows interaction between the instructor and the students. This work is an applicationtype project aiming at developing a teaching tool for Engineering Drawing Course. Multimedia teaching tools have been developed in distance e-learning and offcampus learning circumstances. It is an effective mean of communicating course material wherein the students study on their own at their own pace. However, it is used as an effective supplement to class instruction just the same way as in e-learning or off-campus learning.

Multimedia applications often serve the needs of complex collections of tasks, users, and content. When 
using multimedia for engineering education, one needs to recognize each of the many possible tasks, users, and chunks of content that might be involved. Multimedia can facilitate a much wider range of learning activities and accomplishments than would be expected in a traditional lecture based class. While some of these learning activities can be anticipated in the educational design, many additional activities may result from providing flexible navigation possibilities that allow users to explore the content of a multimedia application in a variety of different manners [5].

Design of a multimedia system involves identifying various navigation structures that allow the contents of different presentation segments to be used to meet the needs of the different learning and exploration tasks [6]. It is also essential to understand the interactions between the information providers, information recipients and the multimedia system.

\section{A. Work phases}

In the first phase of the project, course material is assessed with respect to its multimedia presentation potential. A course outline will be then prepared. The second phase involves the preparation of a set of CAD drawings, computer animations, videos and presentations. These will be used in the teaching of the course and student feedback to the effectiveness and usefulness of the material will be documented. An updated version of the presentations is prepared in the third phase of the project with the update reflecting improvements based on student feedback and on instructors' assessment of the usefulness of the developed material. The final phase involves creating a website for the course.

\section{B. Activities}

The activities conducted in this work are:

1) Course Material Preparation, Selection and Assessment:

The course material was assessed with respect to its multimedia presentation potential and it was concluded that the material at hand, being highly visual, is appropriate for production in a multimedia format. The course outline was thus prepared accordingly.

\section{2) Preparation of CAD Drawings and still images:}

A set of CAD drawings were prepared to serve as a source for the still images that describe in a graphical format the different concepts in teaching the engineering graphics course. These images may be used as stand alone images or may be employed in the presentations. Furthermore, 52 drawing plates were prepared using AutoCAD and made available online via the course website.

\section{3) Computer animations:}

The animations were programmed and designed using Macromedia Flash. Flash is one of the most important tools for creating content for websites. Using the embedded programming language Action Script it has been possible to program end-user dependent interactive tools and tailor-made animations. A main advantage of using Flash is the compact size of the produced animations which allowed quick and easy dissemination though the website. For this work, a total of 10 animations have been created and deployed via the course website.
A set of animated illustrations of the geometric construction procedures employed engineering graphics are prepared. These include animations for the procedures used in bisecting lines or circular arcs, transferring angles, dividing lines into equal or proportional parts, drawing parallel and perpendicular lines, transferring plane figures, drawing circles, arcs and tangents and drawing the different conic sections.

Bearing in mind students needs, each animation contained control buttons for interactivity, a tab that illustrates the required tools for geometric construction and a description area where the procedure is also explained in writing (Figure 1).

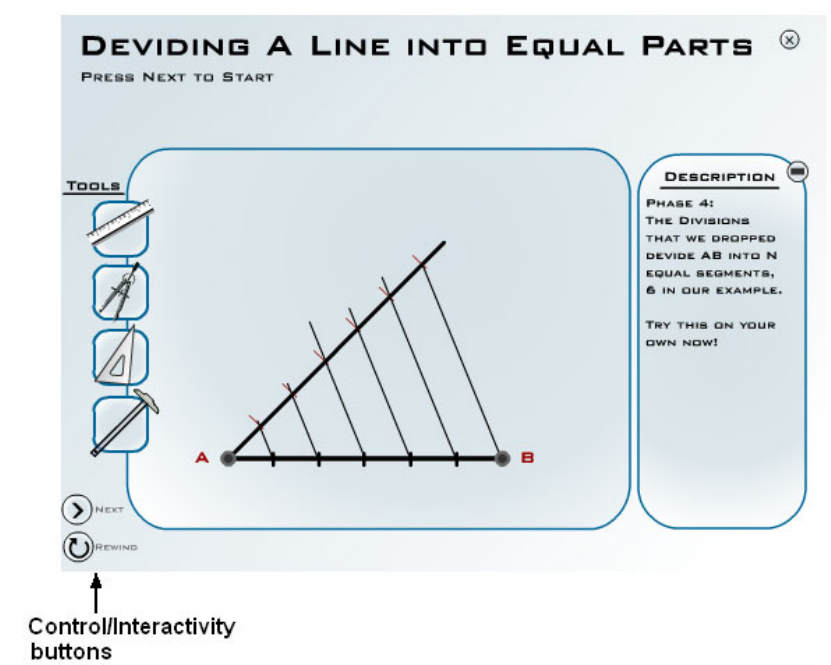

Figure 1. Screen shot of a Flash animation: Dividing a line into equal parts.

Fig. 2 shows the different steps as captured from a different animation (see next page).

\section{4) Video presentations:}

To serve the different needs of students, a set of video presentations have been developed to include audiovisual illustrations of the procedures employed in using the different tools employed in manual drafting. Videos on lettering and sketching techniques, guidelines preparation, using the compass and the divider, using metric, the decimal and the engineering scales, drawing board preparation and usage, using the French curve, the Tsquare and the protractors are being prepared.

5) Presentations:

A set of presentations are prepared covering the educational material. The presentations include an introductory motivational presentation, followed by presentations dedicated to drafting instruments and their proper use, basic drafting and lettering, sketching and line techniques, geometric construction, multi-view drawing, orthographic projections, auxiliary views, points, lines and planes, and descriptive geometry. Only static illustrations produced using AutoCAD are integrated within these presentation to enhance the understanding of the different concepts by the students.

\section{6) Web site development}

The culmination of this work was in creating a website for the course [7]. The site integrates the developed presentations, animations, videos and CAD drawings. It is available for students and faculty in the University of 
Jordan, as well as users worldwide. Ease of navigation, ease of access and direct approach to reach information was kept in mind while designing the website. Fig. 3 shows the main portal for the website.
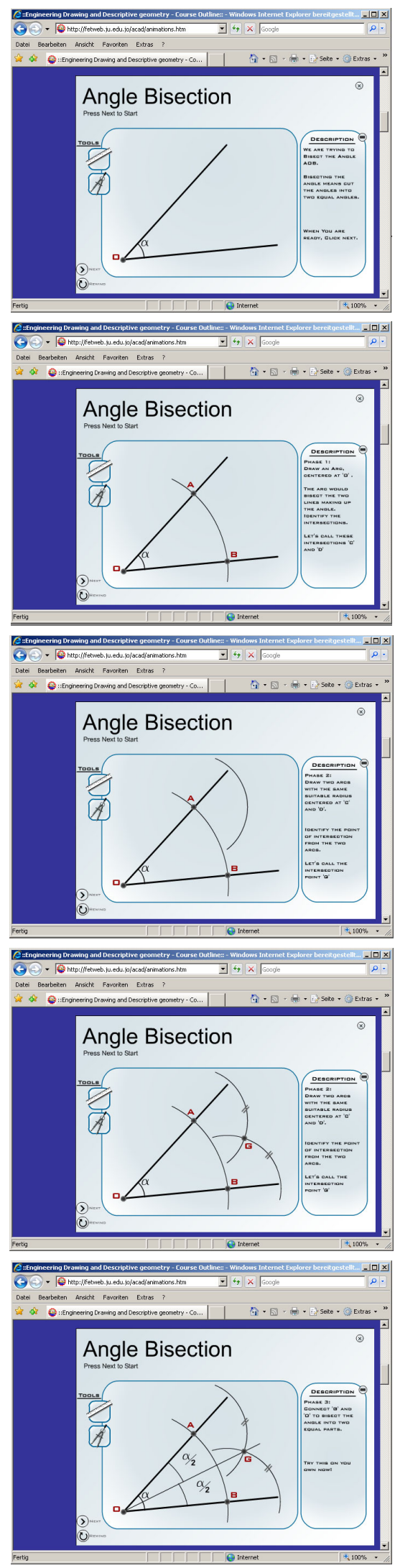

Figure 2. Screen shots of a Flash animation: Angle Bisection.

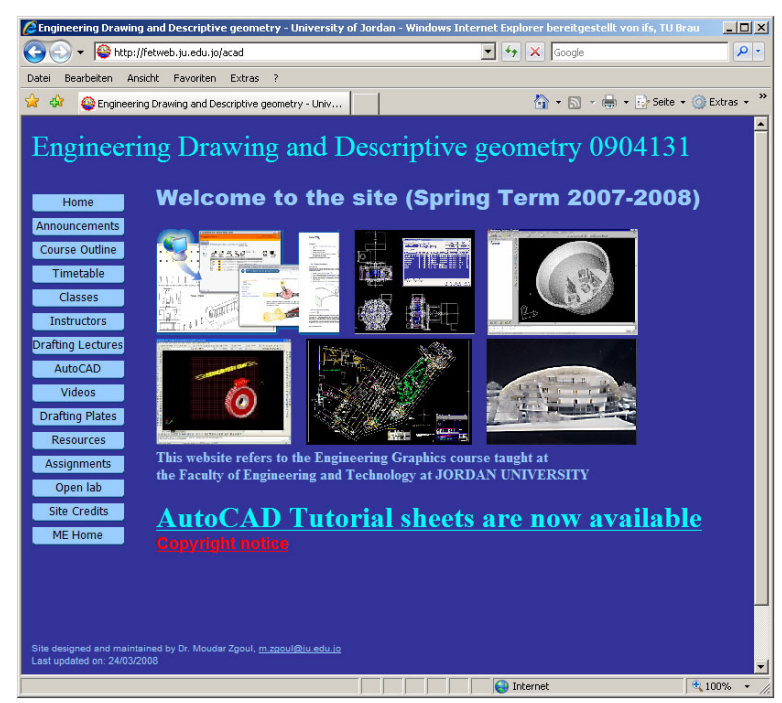

Figure 3. Screen shots of course website.

\section{Students Feedback}

Student feed back was measured via a random sample of students selected in two academic semesters. The survey had a number of questions related to the course and to the website itself. Students were asked/required to give their answers/feedback on the following questions:

1) GPA

2) Expected grade in the course

3) [a] First time to enroll in the course (answer: Yes/NO). [b] If yes, how do you compare the course content to previous time(s) (answer: Yes/No)?

4) Coverage percentage of the CAD software to the other parts of the course (answer: less than 30\%, 40\%-50\%, 60\%-70\%, 70\%-80\%, more than 80\%)

5) Concept of open lab (answer: Excellent, Very good, good, acceptable, not good)

6) Did the open lab concept provide more flexibility in carrying out your work and assignments? (answer: strongly agree, agree, disagree)

7) What do you think about the website? (this question relates to the ease of use and navigation of the website and the usefulness of the information) (answer: Unacceptable, acceptable, good, excellent)

8) How many times do you log on to the website during the week? (answer: none, twice, 3-4 times, 56 times, more than 7 times a week)

9) How do you evaluate the scientific level of the material provided on the website? (answer: not useful, little useful, moderately useful, largely useful)

Answers to the previous questions were analysed and presented in Figure 4.

While $54.35 \%$ of the students who took part in the random survey are re-taking the Engineering Graphics course (question 3a), $54.35 \%$ of this sample believed that the current status of the course with the involved developments is better than the past status. $21.74 \%$ of the sample had a different opinion and $23.91 \%$ of the sample did not have an answer (question 3b). 


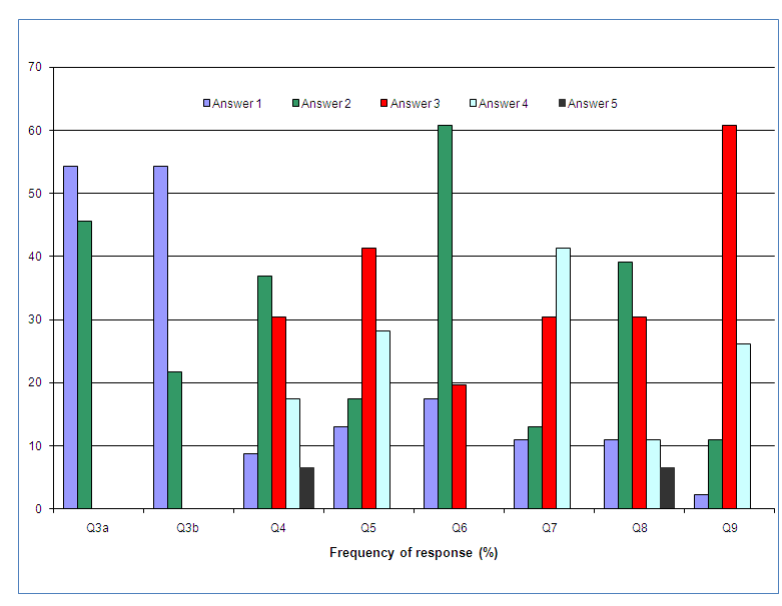

Figure 4. Students answers to survey questionnaire.

The concept of the open lab (self learning using the website, question 5) was found acceptable by $13.00 \%$ of the sample. $17.39 \%$ found it acceptable, while $41.30 \%$ thought it was a good concept. $28.26 \%$ of the sample thought it was an excellent concept.

Regarding flexibility in solving assignments/studying using the open lab concept (website) (covered by question 6), $60.87 \%$ agreed that they had more flexibility, $19.56 \%$ strongly agreed that they had more flexibility while the rest simply disagreed.

Evaluating the website was tackled in questions 7, 8 and 9. Amongst the surveyed sample, $41.30 \%$ thought the idea of having the website was excellent. Only $10.87 \%$ decided that was unacceptable. Also, over $47.00 \%$ of the users have accessed the website at least 4 times a week. $39.00 \%$ have accessed the website twice a week. As for benefiting from the information on the website, $26.08 \%$ have said that they greatly benefited from it. The majority standing at $60.87 \%$ said that the website was moderately beneficial.

\section{PATTERN OF ACCESS TO WeBsite}

Fig. 5 shown total student access to the website over a period of 24 months. The website was initially launched in July 2006 and throughout the assessment period; there has been almost 50,000 page-loads

It can be seen that the access patterns follow the activity patterns of the taught course with the peaks occurring when there was an assessment demand (e.g. interim/final exam).

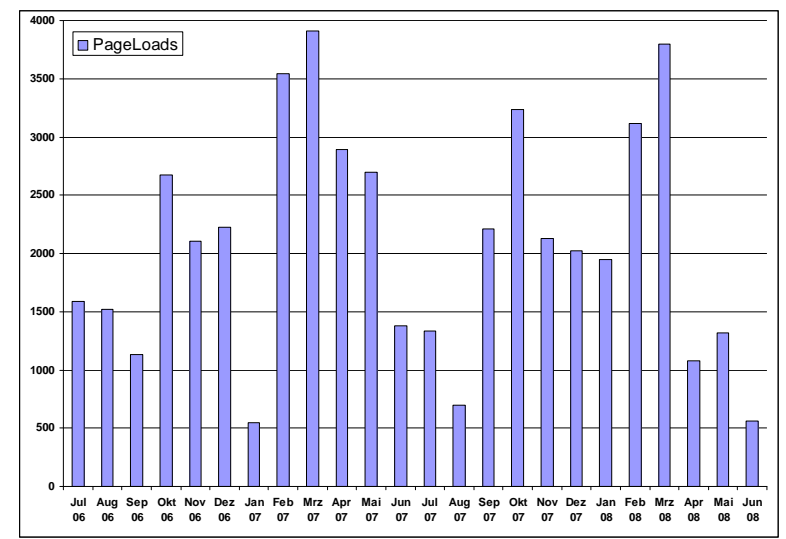

Figure 5. Access patterns to course website.

\section{CONCLUSIONS}

The developed multimedia toolkit included animations, videos and presentations. Those were all integrated in an interactive internet website which is available on the web. This gave a lot of flexibility to the students to do their work and studies at their own convenient time and thus clearing a lot of the recourses for use in other applications. The availability of the material in an electronic selfexplanatory form that is accessed anywhere and at anytime has resulted in an extra benefit; it encouraged students to use computers and to learn basic to advanced skills in using the CAD software by themselves.

Usage statistics of the dedicated website indicates over 50,000 page loads over a period of 2 years. This indicates heavy usage of the website. Furthermore, the website was made available offline to students who do not have access to the internet by means of compact discs.

Results from student feedback and surveys indicated that the majority of the students found the website, with its integrated media, very useful and beneficial.

\section{ACKNOWLEDGEMENTS}

Funding for the development of this work was provided by a grant from the Deanship of Academic research at the University of Jordan. The Authors are grateful to their colleagues at the Mechanical Engineering Department who used the developed website for the course and the accompanying multimedia.

\section{REFERENCES}

[1] Leonid Sheremetov, Adolfo Guzma'n Arenas, "EVA: an interactive Web-based collaborative learning environment," Computers \& Education 39, 161-182, 2002 (doi:10.1016/S03601315(02)00030-1)

[2] E. Schaer, C. Roizard, N. Christmann and A. Lemaitre, "Development and Utilization of an E-Learning course on Heat exchangers at ENSIC," Trans IChemE, Part D, 2006, Education for Chemical Engineers, 1(D0): 82-89. (doi:10.1205/ece06001)

[3] Martin Ebner, Andreas Holzinger, "Successful implementation of user-centered game based learning in higher education: An example from civil engineering," Computers \& Education 49 (2007) 873-890. (doi:10.1016/j.compedu.2005.11.026)

[4] Barbara Tversky, Julie Bauer Morrison and Mireille Betrancourt, "Animation: can it facilitate," Int. J. Human-Computer Studies (2002) 57, 247-262. (doi:10.1006/ijhc.2002.1017)

[5] Jim Carter, "A framework for the development of multimedia systems for use in engineering education," Computers \& Education 39 (2002) 111-128. (doi:10.1016/S03601315(02)00029-5)

[6] ISO 14915-3, (2002). 15-3. Software ergonomics for multimedia user interfaces - media selection and combination. Final draft international standard.

[7] Engineering Drawing and Descriptive geometry. (2008). Available: http://fetweb.ju.edu.jo/ACAD , University of Jordan.

\section{AuTHORS}

M. Zgoul is with University of Jordan, Deanship of Academic Research, he is also an Assistant Professor of Mechanical Engineering. Amman, 11942 Jordan (e-mail: m.zgoul@ju.edu.jo).

M. Kilani is with University of Jordan, he is an Associate Professor of Mecatronics Engineering. Amman, 11942 Jordan (e-mail: mkilani@ju.edu.jo).

This work was supported by the Deanship of Academic Research at the University of Jordan. Manuscript received 06 July 2008. Published as submitted by the authors. 